\title{
Combined trabeculotomy-trabeculectomy compared with primary trabeculectomy for congenital glaucoma
}

\author{
Mark J Elder
}

\begin{abstract}
This paper aimed to assess the outcome of primary trabeculectomy for congenital glaucoma and to compare it with a combined trabeculotomy-trabeculectomy procedure. The combined procedure was assessed using a prospective trial for children with primary glaucoma under the age of 1 year $(n=16)$. The primary trabeculectomy was assessed retrospectively using similar patients treated at the same hospital from 1981 to $1990(n=44)$. After 24 months of follow up, the cumulative chance of success of the primary trabeculectomy was $72 \%$ and this was compared with the combined procedure of $\mathbf{9 3 . 5 \%}$. Primary trabeculectomy achieved good intraocular pressure control for up to 10 years. Follow up for the combined procedure ranged from 19 to 27 months. Complications included hyphaema (4/16 and 4/44) and cataract (0/16 and 3/44). Primary trabeculectomy for congenital glaucoma gives adequate long term success with few complications. The combined procedure may have a higher success rate and this requires further investigation.
\end{abstract}

(Brf Ophthalmol 1994; 78: 745-748)

Congenital glaucoma is an uncommon, severe, and potentially blinding disease. ${ }^{12}$ Management is initially surgical, and is aimed at improving the facility of outflow by incising or cleaving the developmentally abnormal trabecular meshwork. ${ }^{12}$ The classic procedures have been goniotomy ${ }^{3-10}$ and trabeculotomy ab externo. ${ }^{811-16}$ They achieve good results although both are technically demanding and goniotomy requires an adequate view of the angle..$^{3-16}$ In contrast, trabeculectomy has also been shown to achieve adequate control of intraocular pressure in congenital and infantile glaucoma and is technically easier. ${ }^{15-21}$ Therefore, trabeculectomy may be a management option if the cornea is hazy or if there is insufficient experience in goniotomy.

This paper presents the prospective results of a combined trabeculotomy-trabeculectomy procedure for congenital glaucoma. This is compared with primary trabeculectomy for congenital glaucoma in the same population treated at the same hospital.

St John Ophthalmic Hospital, PO Box 19960, Jerusalem, Israel $M$ J Elder

Correspondence to:

Mark Elder, 36 Sinclair Road, London W14 0NH.

Accepted for publication

11 April 1994

\section{Patients and methods}

During 1991 and 1992, I performed a combined trabeculotomy ab externo and trabeculectomy as a primary procedure on all cases of primary congenital glaucoma that came under my care at the St John Ophthalmic Hospital, Jerusalem. All

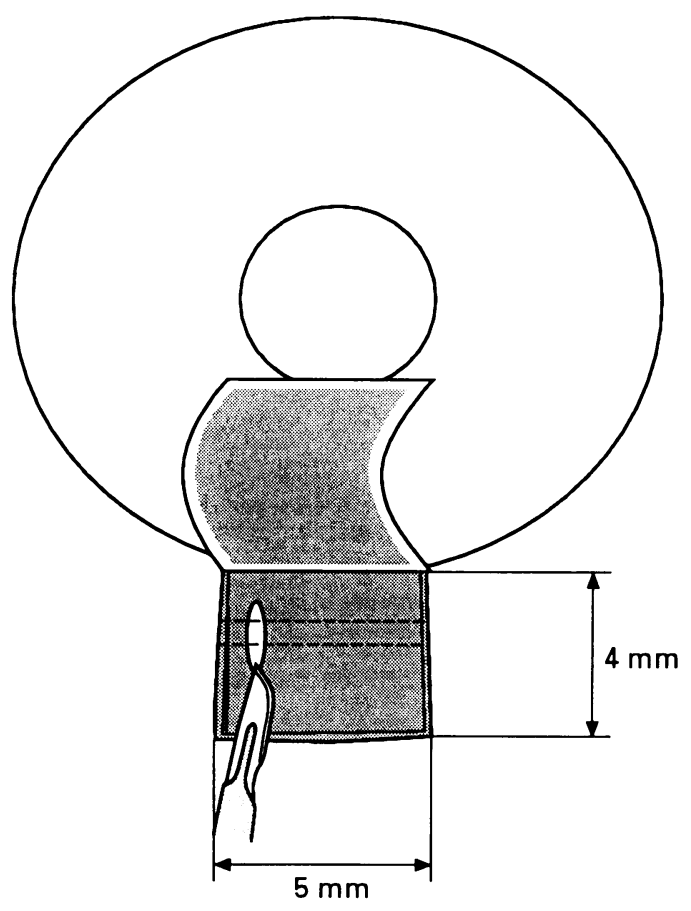

Figure 1 A radial incision is made $1 \mathrm{~mm}$ inside the margin of the scleral flap over Schlemm's canal.

cases were consecutive and no case was excluded from this series.

Congenital glaucoma was defined as that diagnosed under 1 year of age. Intraocular pressure measurements were assessed under anaesthesia using only intravenous ketamine. All surgery was

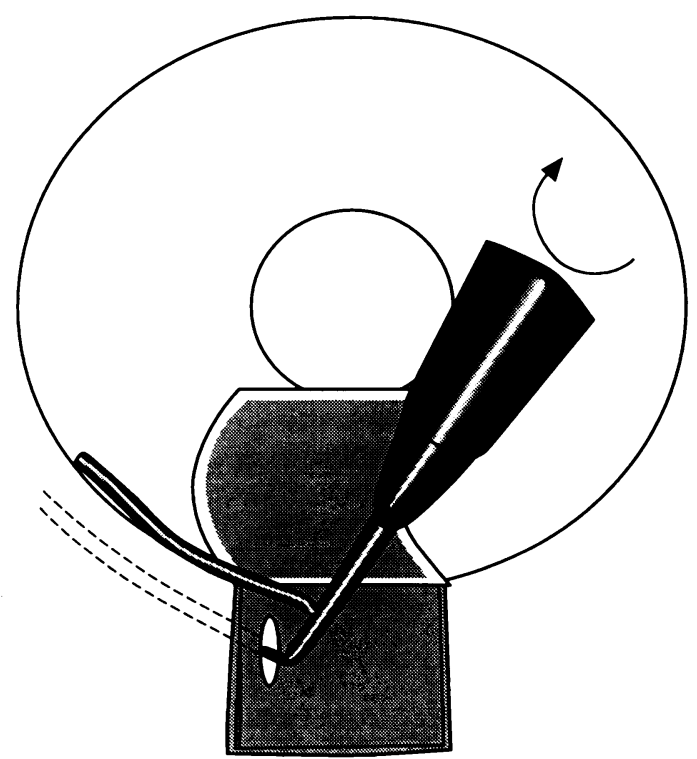

Figure 2 Schlemm's canal was cannulated with a Harms trabeculotome that was then rotated into the anterior chamber to cleave the trabecular meshwork. The canal was cannulated in both directions. 
Figure 3 After the trabeculotomy, a block of scleral tissue was excised. This included Schlemm's canal as for a routine trabeculotomy.

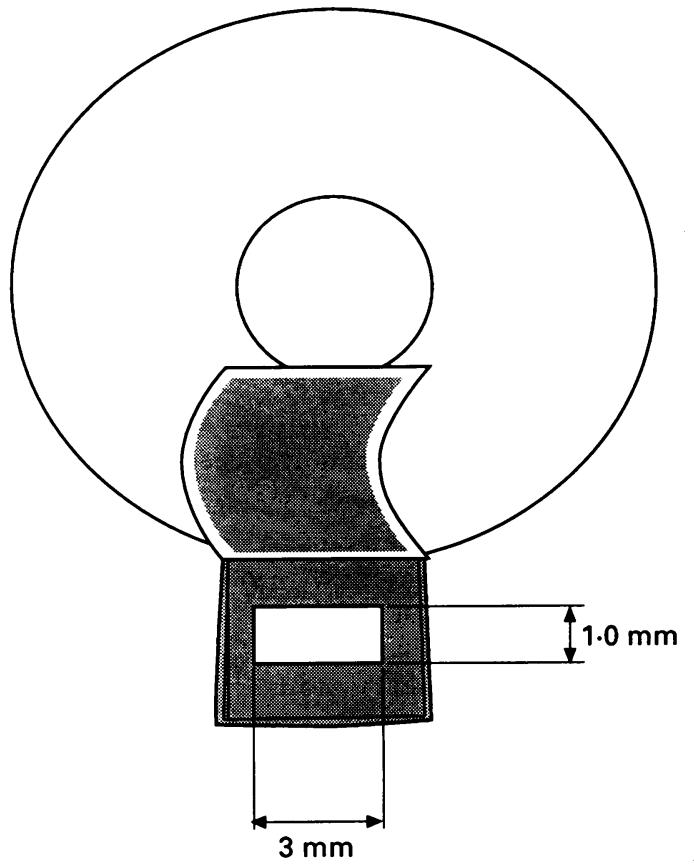

performed using an operating microscope. The surgical technique for the combined trabeculotomy-trabeculectomy procedure was as follows. A limbus based flap of conjunctiva and Tenon's capsule was raised. Tenon's capsule was not excised. A superficial scleral flap, measuring $4 \times 5 \mathrm{~mm}$, was raised at 12 o'clock. The access to Schlemm's canal was made via a radial incision $1 \mathrm{~mm}$ inside the margin of the scleral flap (Fig 1 ). This required high magnification. The incision was gradually deepened until the canal was visible. This was often confirmed by the drainage of aqueous and the appearance of the glistening, longitudinal striations of the inner aspect of the canal. The canal was cannulated with a Harms trabeculotome that was then rotated into the anterior chamber to cleave the trabecular meshwork (Fig 2). The canal was cannulated in both directions; this provided approximately $140^{\circ}$ of angle cleavage. If the canal could not be found, then another radial incision was made adjacent to the other margin of the scleral flap. After the trabeculotomy was performed, a block of scleral tissue measuring approximately $1 \times 3 \mathrm{~mm}$ was removed (Fig 3). This included Schlemm's canal as for a routine trabeculectomy. ${ }^{22} \mathrm{~A}$ peripheral iridectomy was performed. The superficial scleral flap was sutured to the globe with two interrupted $8 / 0$ vicryl sutures. Tenon's capsule was closed with three interrupted sutures of $8 / 0$ vicryl that each included a bite of sclera. The conjunctiva was closed separately with interrupted sutures of $8 / 0$ vicryl. The anterior chamber was reformed with saline via a paracentesis. No viscoelastics were used. A subconjunctival injection of antibiotic and steroid was given at 6 o'clock and the eye padded for 24 hours. Topical medication was started on the first postoperative day and consisted of a proprietary combination of steroid and antibiotic four times a day for 2 weeks only. Postoperatively, a repeat examination under ketamine was performed at 6-8 weeks and thereafter at approximately 4-6 monthly intervals. Follow up also included clinical and orthoptic assessments. The presence of amblyopia was assessed at each visit.
Table 1 Patient data for primary trabeculotomy and combined trabeculotomy-trabeculectomy

\begin{tabular}{lll}
\hline & $\begin{array}{l}\text { Primary } \\
\text { trabeculotomy }\end{array}$ & $\begin{array}{l}\text { Combined } \\
\text { procedure }\end{array}$ \\
\hline Number of eyes & 44 & 16 \\
Number of patients & 25 & 9 \\
Unilateral glaucoma & $6 / 25$ & $2 / 9$ \\
Age (months) (SD) & $4 \cdot 3(3 \cdot 3)$ & $5 \cdot 6(2 \cdot 5)$ \\
Age (range) months & $1-11$ & $2-10$ \\
Follow up (months)(SD) & $48 \cdot 4(34)$ & $21 \cdot 6(3 \cdot 4)$ \\
Follow up (months)(range) & $3-110$ & $19-27$ \\
Initial IOP (mean (SD)) (mm Hg) & $28 \cdot 4(7 \cdot 4)$ & $32 \cdot 6(6 \cdot 9)$ \\
Initial IOP (range)(mm Hg) & $24-43$ & $27-50$ \\
Initial corneal diameter (SD) (mm) & $13 \cdot 1(0 \cdot 7)$ & $12 \cdot 9(0 \cdot 5)$ \\
Initial corneal haze & $36 / 44(82 \%)$ & $9 / 16(56 \%)$ \\
\hline
\end{tabular}

Forty four eyes of 25 children under the age of 1 year had a primary trabeculectomy. This represented all cases of primary trabeculectomy for congenital glaucoma performed at the St John Ophthalmic Hospital from 1981 to 1990 . The trabeculectomy was of a conventional type $\mathrm{e}^{22}$ and no case has been excluded. The data of these 44 eyes are a reanalysis of a previous retrospective study. ${ }^{16}$ This previous report showed that, overall, trabeculectomy was more successful than goniotomy or trabeculotomy for the Palestinian Arab children. Three eyes had concomitant cataracts present when the glaucoma was diagnosed, no eye had Sturge-Weber syndrome, and all children were otherwise normal.

\section{Results}

Sixteen eyes of nine patients were treated with the combined trabeculotomy-trabeculectomy. Follow up was prospective. All patients were treated surgically as the primary treatment with one exception (see below). The characteristics of the patients are given in Table 1. The corneal diameter was measured horizontally and reduced corneal transparency was defined as that which was apparent to the naked eye. Using the classification of Hoskins and Shaffer, ${ }^{23}$ isolated trabeculodysgenesis was present in $9 / 16$ eyes and irido-trabeculodysgenesis in $7 / 16$ eyes. No eye had other ocular abnormalities. One child had failure to thrive owing to giardiasis, otherwise all children were systemically normal and well.

The surgery for combined trabeculectomytrabeculotomy was routine in all cases. Hyphaema occurred in 4/16 eyes; two from the cleavage of angle vessels, one from performing the peripheral iridectomy, and one was initially apparent on the first postoperative day. There were no other perioperative or postoperative complications. There were no flat anterior chambers postoperatively. The child with giardiasis and unilateral glaucoma was unable to proceed with elective surgery as it developed tachyarrhythmias during induction of anaesthesia. Therefore topical pilocarpine was given for 1 month while the child's general health improved. Topical $B$ blockers were deemed inappropriate in view of the previous cardiac arrhythmias. Routine surgery was then performed without any problems. At the 6 week examination under ketamine, the intraocular pressure had risen to $37 \mathrm{~mm} \mathrm{Hg}$. This was the only case where the intraocular pressure was not maintained at less than $21 \mathrm{~mm} \mathrm{Hg}$ on no medication. The mean intraocular pressure for the other 15 eyes was 


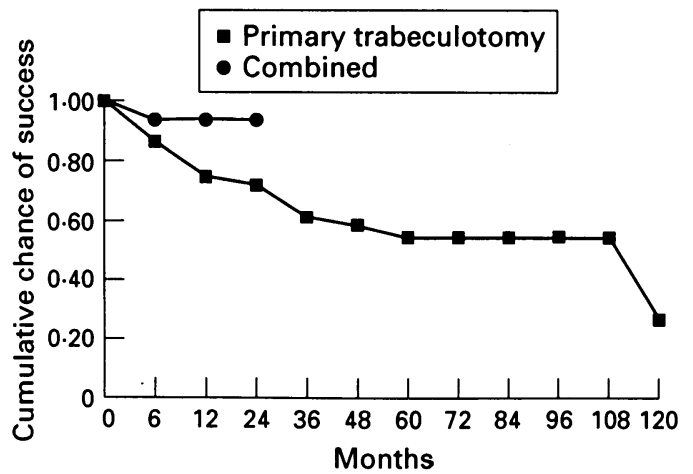

Figure 4 Life table results of cumulative chance of success of each procedure. Success was defined as IOP $<21 \mathrm{~mm} \mathrm{Hg}$ on no medication.

$14 \cdot 4(\mathrm{SD} 2 \cdot 6) \mathrm{mm} \mathrm{Hg}$ with a range of $10-18 \mathrm{~mm}$ $\mathrm{Hg}$, taken at the last clinic visit. At the same time, the mean horizontal corneal diameter for these 15 eyes was $13 \cdot 2(0 \cdot 5) \mathrm{mm}$ and all corneas had normal transparency. There were no late ocular complications although one child developed a convergent squint that was successfully managed with occlusion and squint surgery. No child developed cataract.

Additional to these 16 eyes were two eyes of one child. At the time of surgery, Schlemm's canal was not found in either eye and therefore just a trabeculectomy was performed. This achieved bilateral intraocular pressures less than $21 \mathrm{~mm} \mathrm{Hg}$ on no medication with 23 months' follow up. This case is not reported in the above series of 16 eyes but reflects that Schlemm's canal was not overtly found in $2 / 18(11 \%)$ consecutive cases.

The primary trabeculotomy case details are given in Table 1 . Hyphaema occurred in $4 / 44$ eyes, otherwise there were no perioperative or early postoperative complications. There was no vitreous loss. Iridotrabeculodysgenesis was described in 3/44 patients, while the rest had presumed isolated trabeculodysgenesis. Late complications included one retinal detachment, one subluxed lens, and three cataracts that required lensectomy. Two cataracts occurred in one child and were diagnosed 6 and 9 months after the trabeculectomies. The other cataract occurred 3 years after surgery. It could not be determined whether they were associated with the surgery.

Surgical success was defined as an intraocular pressure less than $21 \mathrm{~mm} \mathrm{Hg}$ on no medication. The life table analysis of cumulative chance of success for both procedures ${ }^{24}$ is presented in Figure 4.

\section{Discussion}

Raised intraocular pressure occurs because of an imbalance of aqueous production and aqueous outflow via the trabecular meshwork and the uveoscleral pathway. In congenital glaucoma, the intraocular pressure is raised owing to a developmental defect in the trabecular meshwork that causes a decreased facility of outflow. ${ }^{26}$ Therefore, traditional surgery for congenital glaucoma has centred on incising the trabecular meshwork. This can be achieved by incising the meshwork $\mathrm{ab}$ interno or ab externo, with goniotomy or trabeculotomy respectively.

Goniotomy is a successful procedure that does not disturb the conjunctiva. ${ }^{3-10}$ This is an advantage if filtering surgery is subsequently needed. However, the procedure requires an adequate view of the trabecular meshwork if it is to be safe and effective. This may exclude up to $50 \%$ of cases because of reduced corneal clarity. ${ }^{1216}$ In comparison, trabeculotomy is approximately equally effective at controlling intraocular pressure and can be performed when there is reduced corneal clarity..$^{810-16}$ Therefore, it is applicable to a larger number of cases. The disadvantage is that Schlemm's canal may not be cannulated appropriately. The canal is not found in $11-15 \%$ of procedures ${ }^{11}{ }^{16}$ and a further uncertain percentage may be unknowingly, incorrectly cannulated. This may be caused by surgical inexperience, abnormal anatomy, or hypoplasia of the canal. ${ }^{112728}$ Further, the meshwork tissues may gradually overgrow the trabeculotomy site ${ }^{29}$ and this may explain some of the declining success with time. ${ }^{16}$ Clearly, neither goniotomy nor trabeculotomy are ideal for all patients and all surgeons.

Primary trabeculectomy has been an uncommon operation for congenital glaucoma. However, it is a procedure that most ophthalmologists are familiar with and it is technically easier than goniotomy or trabeculotomy. Limited previous reports show encouraging results. ${ }^{1517-21}$ Only Beauchamp and Parks report disparaging success rates $(50 \%)$ and significant numbers of complications. ${ }^{30}$ Their cases were almost all secondary procedures. In the West Bank and Gaza Strip, trabeculectomy overall was more successful than goniotomy or trabeculotomy. ${ }^{16}$ In this study, primary trabeculectomy has been a successful procedure over long periods given that the data are retrospective and that several surgeons were involved. There have been no cases of late endophthalmitis although this remains a risk. The aetiology of the cataracts remain uncertain. The criterion for success has also been defined as a control of intraocular pressure less than $21 \mathrm{~mm}$ $\mathrm{Hg}$. This has almost universally been the accepted criterion of success whereas the ultimate goal is good visual function. This includes good visual acuity, normal visual fields, and otherwise normal eyes.

The technique of combined trabeculotomytrabeculectomy has theoretical and practical advantages. It is less dependent on corneal clarity than goniotomy and therefore is applicable to all primary surgery in congenital glaucoma. It deals with the primary problem of increased trabecular meshwork resistance and provides an additional pathway for the outflow of aqueous via the trabeculectomy bleb site. Despite these two separate mechanisms of increasing outflow, overdrainage was not seen in the short or the long term. Technically, the technique requires minimal extra surgical time over just trabeculotomy or just trabeculectomy and the complications were no different from either procedure on its own. ${ }^{16}$ The accurate location of Schlemm's canal allows the inner window of the trabeculectomy to be placed correctly and this has theoretical advantages. A failure to adequately cannulate Schlemm's canal, either overtly or covertly, 
should not lead to total failure as there is retention of the trabeculectomy drainage mechanism.

The combined trabeculotomy-trabeculectomy procedure has been described previously. Two series describe its use in Sturge-Weber syndrome $(\mathrm{n}=19$ and $\mathrm{n}=5) .{ }^{31}{ }^{32}$ It has also been used for infantile glaucoma by Turut et $a l^{33}(\mathrm{n}=17)$, Burke and Bowell ${ }^{18}(\mathrm{n}=2)$, Maul et al $^{34}(\mathrm{n}=1)$, and Luntz ${ }^{35}$ (no numbers given). In this current series, all cases had primary congenital glaucoma diagnosed within the first year of life. The surgery was performed by a single experienced surgeon using facilities equal to the best available in the United Kingdom. For this group of patients, the combined procedure has been very successful. The cumulative chance of success at 24 months was $93 \cdot 5 \%$ and this compares with Turut et al's $70 \%$ success. ${ }^{35}$ It is possible that this success is solely the result of the trabeculotomy as similar results have been reported for trabeculotomy alone. ${ }^{12}$ However, for this population, a previous study showed that trabeculotomy had only a $51 \%$ cumulative chance of success at 24 months. ${ }^{16}$ Similar results have been found in children from Saudia Arabia. ${ }^{15}$ It is also possible that the success is due to just the trabeculectomy. However, this study has shown that primary trabeculectomy in the same population had only $72 \%$ chance of success at 24 months. The comparison of the preoperative status of primary trabeculectomy and the combined procedure (Table 1) reveals that they are broadly similar. The combined group had more iridotrabecular dysgenesis but there are difficulties in assessing this retrospectively in the primary trabeculectomy group. The combined procedure group were slightly older and had slightly more clear corneas.

Another explanation for the combined procedure success is that it provides two major additional outflow pathways, the trabeculotomy site and the bleb site. Therefore, the intraocular pressure may remain normal even if one or other of the pathways failed. Only if both failed would the intraocular pressure rise. Hypothetically, if the chance of success of each procedure was $50 \%$ and if the individual pathway chance of failure was an independent event, then the chance of success would be $75 \%$.

Goniotomy and trabeculotomy remain the standards in congenital glaucoma. Both procedures are successful and have been assessed in large numbers over long periods of time. ${ }^{3-16}$ Goniotomy has the ultimate advantage because it does not disturb the conjunctiva, but it requires an adequate surgical view, and an experienced surgeon. This paper confirms that primary trabeculectomy for congenital glaucoma also has reasonable long term success with few complications. It is particularly applicable to situations where there is no expertise in goniotomy or trabeculotomy. The combined trabeculotomytrabeculectomy procedure has some theoretical and practical advantages over these other techniques. The results are encouraging but the numbers are small. A prospective study is required with larger numbers and longer follow up to determine further the role of this procedure in congenital and infantile glaucoma.

1 Kolker A, Hetherington J. Becker-Shaffer's diagnosis and therapy of the glaucomas. St Louis: Mosby, 1976.

2 De Luise VP, Anderson DR. Primary infantile glaucoma. Surv Ophthalmol 1983; 28: 1-19.

3 Barkan O. Technique of goniotomy. Arch Ophthalmol 1938; 19: 7-223.

4 Barkan O. Goniotomy for the relief of congenital glaucoma. Brf Ophthalmol 1948; 32: 701-28.

5 Broughton WL, Parks MM. An analysis of treatment of congenital glaucoma by goniotomy. Am $\mathcal{F}$ Ophthalmol 1981; 91: 566-72.

6 Shaffer RN. Prognosis of goniotomy in primary infantile glaucoma (trabeculodysgenesis). Trans Am Ophthalmol Soc 1982; 80: 321-5.

7 Shaffer RN, Hoskins HD. Montgomery lecture. Goniotomy in the treatment of isolated trabeculodysgenesis (primary congenital developmental glaucoma). Trans Ophthalmol Soc UK 1983; 103: 581-5.

8 McPherson SD Jr, Berry DP. Goniotomy vs external trabeculotomy in developmental glaucoma. Am $\mathcal{F}$ Ophthalmol 1983; 95: 427-31.

9 Anderson DR. Trabeculotomy compared to goniotomy for glaucoma in children. Ophthalmology 1983; 90: 805-6.

10 Hoskins HD, Shaffer RN, Hetherington J. Goniotomy vs trabeculotomy. $\mathcal{F}$ Pediatr Ophthalmol Strabismus 1984; 21: trabecu.

11 Harms $\dot{H}$, Dannheim R. Epicritical consideration of 300 cases of trabeculotomy ab externo. Trans Ophthalmol Soc UK 1970; 89: 491-9.

12 Luntz MH, Livingston DG. Trabeculotomy ab-externo and trabeculotomy in congenital and adult-onset glaucoma. $A m \mathcal{F}$ Ophthalmol 1977; 83: 174-9.

13 Luntz MH. The advantages of trabeculotomy over goniotomy. f Pediatr Ophthalmol Strabismus 1984; 21: 150-3.

14 Quigley HA. Childhood glaucoma: results with trabeculotomy and study of reversible cupping. Ophthalmology 1982; 89: 219-26.

15 Debnath SC, Teichmann KD, Salamah K. Trabeculectomy versus trabeculotomy in congenital glaucoma. $\mathrm{Br} \mathcal{F} O$ phthalmol 1989; 73: 608-11.

16 Elder MJ. Congenital glaucoma in the West Bank and Gaza strip. Br f Ophthalmol 1993; 77: 413-6.

17 Rao KV, Sai CM, Babu BV. Trabeculectomy in congenital glaucoma. Indian f Ophthalmol 1984; 32: 439-40.

18 Burke JP, Bowell R. Primary trabeculectomy in congenital glaucoma. BrF Ophthalmol 1989; 73: 186-90

19 Miller MH, Rice NSC. Trabeculectomy combined with B irradiation for congenital glaucoma. BrF Ophthalmol 1991; 75: 584-90.

20 Dascotte JC, Asseman R, Francois P, Houliez T, Huron JC, Castier $\mathrm{P}$, et al. Traitement chirurgical du glaucome congenital. Resultats a long terme. F Fr Ophtalmol 1991; 14: 229-33.

21 Werther DE. Trabeculectomy in congenital glaucoma. Excerpta Medica 1979; 2: 1517-8.

22 Cairns JE. Trabeculectomy: preliminary report of a new method. Am $\mathcal{F}$ Ophthalmol 1968; 66: 673-9.

23 Hoskins DH, Shaffer RN, Hetherington J. Anatomical classification of the developmental glaucomas. Arch Ophthalmol 1984; 104: 1331-6.

24 Elwood MJ. Causal relationships in medicine. A practical system for critical appraisal. Oxford: Oxford University Press, 1988: 296-307.

25 Kahn HA, Sempos CT. Statistical methods in epidemiology. Monographs in epidemiology and biostatistics. Vol 12. Oxford: Monographs in epidemiology and biostatist
Oxford University Press, 1989: 168-98.

26 Anderson DR. The development of the trabecular meshwork and its abnormality in primary infantile glaucoma. Trans Am Ophthalmol Soc 1981; 79: 481-5.

27 Wright JD, Robb RM, Dueker DK, Boger WP. Congenital glaucoma unresponsive to conventional therapy: a clinicopathological case presentation. $\mathcal{F}$ Pediatr Ophthalmol Strabismus 1983; 20: 172-9.

28 Spencer WH. Histological evaluation of microsurgical techniques. Trans Am Acad Ophthalmol Otolaryngol 1972; 76:

29 Lalive-d'Epinay S, Reme C. Klinische und morphologische untersuchgen eines kongenitalen glaukoms bei okulo-digitodentalem syndrom. Klin Monatsbl Augenheilkd 1976; 168: dentalem 113 .

30 Beauchamp GR, Parks MM. Filtering surgery in children: barriers to success. Ophthalmology 1979; 86: 170-80.

31 Agarwal HC, Sandramouli S, Sihota R, Sood NN. SturgeWeber syndrome: management of glaucoma with combined trabeculotomy and trabeculectomy. Ophthalmic Surg 1993; 24: $399-402$.

32 Board RJ, Shields MB. Combined trabeculotomytrabeculectomy for the management of glaucoma associated with Sturge-Weber syndrome. Ophthalmic Surg 1981; 12: 813-7.

33 Turut P, Ribstein G, Milazzo S, Madelain J. L'intervention combinee trabeculotomie trabeculectomie dans le glaucome

34 Maul E, Strozza L, Reyes C. The outfow pathway in congenital glaucoma. Am $\mathcal{F}$ Ophthalmol 1980; 89: 667-73.

35 Luntz MH. The choice of surgical procedure in congenital, infantile and juvenile glaucoma. $\mathcal{f}$ Ophthalmic Nurs Technol 1990; 9: 100-1. 